\section{Reward research outreach in Japan}

The Japan Science and Technology Agency last month reported that only $64 \%$ of almost 9,000 surveyed Japanese scientists communicate results outside the scientific community. This is surprising: since 2010, the government has urged the researchers it funds to improve communication with the tax-paying public - particularly after the March 2011 tsunami and nuclear accident at Fukushima.

Of the $36 \%$ of researchers who did not participate in outreach, many cited administrative overload and a lack of resources and time. The biggest issue among these scientists was that they felt there was no personal advantage in communicating their results to the public. This is because researcher performance in Japan is evaluated solely on the number of journal publications, so time and effort spent on science communication will not help scientists to secure funding, promotion or employment.

The government needs to recognize that scientific outreach activities are valid experiences for funding and job applications. Japan's researchers, in turn, should recognize that communicating with the public provides its own reward in the form of society's acknowledgement of their work. Amane Koizumi National Institute for Physiological Sciences, Aichi, Japan. amane@nips.ac.jp Yuko Morita National Museum of Emerging Science and Innovation (Miraikan), Tokyo, Japan. Shishin Kawamoto Hokkaido University, Hokkaido, Japan.

\section{Flanders overrates impact factors}

A renewed decree on research funding last year by the government of Flanders in northern Belgium advised that $40 \%$ of research evaluation should be based on bibliometric data. This involves a complex calculation that includes the number of publications and citations, and the impact factors for the journals of publication (see go.nature.com/mt9srg; in Dutch). We question the merits of this strategy, given the debatable value of impact factors in gauging research quality (see, for example, B. Alberts Science 340, 787; 2013).

The Flemish Interuniversity Council in fact advised Flemish universities in 2010 to reduce the importance of bibliometric data when weighing up researchers for appointment or promotion. In practice, however, such data have become even more important.

It is time to heed the widely recognized risk of overrating the quantity of scientific publications, which can compromise research quality and integrity.

Karen Stroobants, Simon

Godecharle Research

Foundation Flanders (FWO) and

University of Leuven, Belgium.

karen.stroobants@chem.kuleuven.be

Sofie Brouwers FWO and Vrije

Universiteit Brussel, Belgium.

\section{Time-lapsed awards for excellence}

The number of scientific prizes has proliferated in the past 20 years (see Nature 498, 152-154; 2013). But once a scientist has published a seminal contribution, how long is it before these glittering symbols of recognition come through?

Occasionally, recognition comes early in a scientific career. For example, the biologist Thomas Henry Huxley was elected as a fellow of the Royal Society in London in 1851 at age 26, and William Lawrence Bragg won the Nobel Prize in Physics in 1915 when he was just 25 . But these may be exceptions.

We looked at 466 recipients of Nobel prizes in physics, chemistry, and physiology or medicine, awarded from 1901 to 2000 , using a biographical encyclopedia that also lists all other major institutional awards won by an individual (G. T. Kurian The Nobel Scientists, Prometheus; 2002). These include prizes such as the Davy Medal, the Max Planck Medal and the Canada Gairdner International Award.

Using the year in which laureates produced their Nobel-prizewinning work as an indicator for the timing of their peak scientific achievement, we calculated the average lag time in each field between this and the timing of the Nobel prize and other major awards.

Our investigations indicate that recognition is conferred relatively rapidly. In physics, the lag was just 5 years; in chemistry, 9 years; and in physiology or medicine, it was 11 years. It seems that important discoveries in physics, and perhaps in chemistry, are more easily defined than in physiology or medicine, so their merits are more swiftly recognized.

Ho Fai Chan, Benno Torgler Queensland University of Technology, Brisbane, Australia. benno.torgler@qut.edu.au

\section{Joint Indian initiative creates tiger corridor}

India harbours $60 \%$ of the world's wild tigers but, as elsewhere, populations are declining because of habitat destruction. An initiative between an Indian state government and civil society is set to counteract this trend, and offers an instructive conservation model.

Karnataka state in southern India has implemented several effective tiger-conservation strategies. However, the protected areas that shelter tigers are disjointed and isolated, and tiger populations are becoming increasingly fragmented.

Habitat connectivity between populations is essential for the tiger's future survival. It aids dispersal of tigers from source sites, enables genetic exchange between populations and helps to maintain meta-populations.

In response, the state government is actively linking tiger populations by identifying ecologically important habitats and designating them as protected areas to ensure longterm habitat protection.

For example, in May 2013 it established the 906-squarekilometre Malai Mahadeshwara Wildlife Sanctuary, creating a $6,500-\mathrm{km}^{2}$ contiguous network of protected areas - the largest in the country. Over the past 19 months, the state government has added nearly $3,000 \mathrm{~km}^{2}$ of tiger habitat to the network.

This extended landscape should be able to host a connected population of some 500 tigers.

Sanjay Gubbi Panthera, New York, USA; and Nature Conservation Foundation, Mysore, India. sanjaygubbi@gmail.com H. C. Poornesha Nature Conservation Foundation, Mysore, India.

\section{Comparing science and music is unsound}

Stephane Detournay suggests that both scientific research and music composition undergo phases of "onset, development, refinement and exposition" (Nature 499, 245; 2013). But so do hedge-fund management and tomato farming.

One thing that binds music and science is the idea that sincere, personal investment in one's work is good. Yet music is mainly about evoking, interpreting and savouring emotions, whereas science is essentially the pursuit of truth. Justin Jee New York University, New York, USA. justin.jee@med.nyu.edu

CONTRIBUTIONS Correspondence may be sent to correspondence@ nature.com after consulting go.nature.com/cmchno 